\title{
Honeydew production and honeydew sugar composition of polyphagous black bean aphid, Aphis fabae (Hemiptera: Aphididae) on various host plants and implications for ant-attendance
}

\author{
Melanie K. FISCHER, Wolfgang VÖLKL and Klaus H. HOFFMANN* \\ Department of Animal Ecology I, University of Bayreuth, 95440 Bayreuth, Germany
}

Keywords. Aphids, summer host, winter host, honeydew, melezitose, ant-attendance

\begin{abstract}
The black bean aphid, Aphis fabae, is polyphagous and its life cycle involves seasonal migration between summer and winter host plants. The aphids are regularly tended by honeydew-collecting ants. This study investigates whether differences exist in honeydew production and honeydew sugar composition for $A$. fabae subspecies feeding on various host plants and whether such differences reflect differences in the intensity of ant-atttendance (Lasius niger).

A. $f$. fabae feeding on the perennial summer host, Tanacetum vulgare, produced twice the amount of honeydew (ca. $110 \mu \mathrm{g}$ per aphid $\mathrm{h}^{-1}$ ) than when feeding on the annual host plants Vicia faba or Chenopodium album. Honeydew production of $A$. $f$. cirsiiacanthoides feeding on the creeping thistle Cirsium arvense was the highest measured in this study (ca. $150 \mu \mathrm{g}$ per aphid $\cdot \mathrm{h}^{-1}$ ). Total sugar concentration in the honeydew of $A$. f. fabae did not differ when feeding on various summer hosts, whereas the honeydew of A. f. cirsiiacanthoides on $C$. arvense contained a significantly higher amount of total sugars. The trisaccharide melezitose was the dominant sugar in all the honeydew samples, except for the honeydew of $A$. f. fabae and A. f. evonymi feeding on the woody winter host plant Evonymus europaeus. The highest proportion of melezitose ( $80 \%$ of total sugars) was found in the honeydew of $A$. f. cirsiiacanthoides feeding on $C$. arvense. In this subspecies, the intensity of ant-attendance was also highest. The results confirm our hypothesis, that the sugar richness of the honeydew (rate of honeydew secretion $\times$ total sugar concentration) along with the presence of the attractant sugar melezitose are the critical factors in determining the extent of ant-attendance.

In $A$. f. fabae feeding on the spindle tree E. europaeus, the total sugar concentration of the honeydew as well as the sugar composition differed significantly between generations.
\end{abstract}

\section{INTRODUCTION}

Aphids (Aphidoidea) have commonly developed mutualistic relationships with ants. The ants cover their carbohydrate demand by collecting "honeydew", which is excreted by the aphids as a sweet waste product of their sugar-rich but amino acid-poor diet of phloem sap (Way, 1963). Ants in return defend the aphids from natural enemies. In general, the intensity of ant-aphid mutualism is positively correlated with honeydew quantity and quality as well as the sugar demand of the ants (Bristow, 1984; Bonser et al., 1998; Fischer et al., 2001). Honeydew is an aqueous solution consisting mainly of various sugars and amino acids (Auclair, 1963; Maurizio, 1985). Honeydew production and honeydew composition vary considerably between aphid species (e.g. Hendrix et al., 1992; Völkl et al., 1999) but may also vary within a particular aphid species in an age-specific pattern (Hertel \& Kunkel, 1977; Fischer et al., 2002) or when feeding on different host plants. Douglas (1993) demonstrated differences in the amino acid pattern of the polyphagous aphid species Aphis fabae on different host plants. Fischer \& Shingleton (2001) showed that the honeydew of Chaitophorus populialbae and C. populeti contained higher proportions of the trisaccharide melezitose when feeding on Populus tremula than on $P$. alba. Finally, honeydew production and honeydew composition may vary within a particular species on a definite host plant in response to changes in the aphid's interaction with ants (Del-Claro \& Oliveira, 1993; Fischer et al., 2001).

The black bean aphid, A. fabae, is regularly tended by honeydew-collecting ants and benefits from this mutualism. The life cycle of the host-alternating $A$. fabae involves seasonal migration between unrelated summer (herbaceous or secondary) and winter (woody or primary) host plants. In autumn, winged females are produced (gynoparae) which locate the primary host, the spindle tree Evonymus europaeus and deposit sexual females that develop, mate and lay eggs before leaf fall. During the summer, $A$. fabae is polyphagous. For example, summer forms (virginoparae) of the sub-species $A$. $f$. fabae are able to colonize approximately 100 plant species (Powell \& Hardie, 2001). Under field conditions $A$. f. fabae is not found on the winter host plant during the summer, but they will feed and reproduce on spindle trees in laboratory tests (Powell \& Hardie, 2000). Another subspecies of A. fabae, A. f. cirsiiacanthoides colonizes the creeping thistle, Cirsium arvense, as a summer host, whereas the non-host alternating subspecies $A$. $f$. evonymi is found on spindle trees throughout the whole year.

This study investigates whether differences exist in the honeydew composition of $A$. fabae subspecies feeding on various hosts and whether such differences in honeydew composition may result in differences in ant-attendance.

\footnotetext{
* Corresponding author; e-mail: Klaus.Hoffmann@uni-bayreuth.de
} 
First, we examined the honeydew production and the honeydew sugar composition of $A$. $f$. fabae on various host plants, a primary host, E. europaeus and three herbaceous summer hosts, the goosefoot Chenopodium album (Chenopodiaceae), the tansy Tanacetum vulgare (Asteraceae), and the broad bean Vicia faba (Fabaceae). Second, we compared the sugar composition of the honeydew from three $A$. fabae subspecies, A. f. fabae, $A$. $f$. cirsiiacanthoides, and $A$. $f$. evonymi feeding on their respective summer hosts, and third we investigated the relationship between honeydew composition in $A$. fabae ssp. colonies on four herbaceous summer host plants and ant-attendance. Finally, we analyzed the sugar composition of the honeydew during the life cycle of $A$. $f$. fabae on its winter host E. europaeus.

\section{MATERIAL AND METHODS}

\section{Plant and insect material}

Chenopodium album plants were grown from seeds in plant pots (diameter $25 \mathrm{~cm}$ ) in a defined garden soil (obtained from Bayreuth Botanical Garden) to standardize plant quality. The pots were kept in a climate chamber $\left(20^{\circ} \mathrm{C}, 16 \mathrm{~L}: 8 \mathrm{D}, 60 \%\right.$ relative humidity, 8000 lux from the ceiling) where they grew to a height of about $20 \mathrm{~cm}$ within two to three weeks. Vicia faba (cv minor) plants were grown from seeds as described earlier (Engel et al., 2001). All plants were about $20 \mathrm{~cm}$ tall when used in the experiments. The two perennial herbs Cirsium arvense plants (minimum height of $30 \mathrm{~cm}$ ) and tansy (Tanacetum vulgare) were obtained from rhizomes dug out from ruderal areas at the University campus and potted in garden soil (diameter of pots $30 \mathrm{~cm}$ ). We only used plants that were about to flower for the experiments. All plants were 40 to $50 \mathrm{~cm}$ tall (Fischer et al., 2002). Young spindle trees (Evonymus europaeus) $(50$ to $70 \mathrm{~cm}$ tall) were obtained from the field (Neunkirchen, $10 \mathrm{~km}$ east of Bayreuth) and potted in defined soil.

To obtain an A.f. fabae stock culture, one large colony ( $>100$ individuals) was collected in the field. Twenty-five to 30 individuals of this colony were transferred separately to potted tansy plants in a climate chamber (for conditions, see above). For our experiments, aphids from this stock culture were transferred to their various host plants and used when the respective colonies reached a size of 50 to 100 individuals. In the case of A.f. cirsiiacanthoides, aphids were collected from $C$. arvense in the field and directly transferred to the experimental plants. The potted plants were kept at a sunny site in earth-filled planting pots $(1 \mathrm{~m}$ $\times 1 \mathrm{~m} \times 0.5 \mathrm{~m} ; 1 \times \mathrm{b} \times \mathrm{h}$ ) each of which contained a nest of the common garden ant Lasius niger (approx. colony size: 1000-2000 workers). In each pot, the plants were placed close to the nest in waterfilled bowls to prevent uncontrolled antattendance. The experiments were carried out between end of June and mid-August.

For the determination of the honeydew composition of $A$. $f$. fabae on E. europaeus during their life cycle and for the studies of $A$. f. evonymi on E. europaeus, established spindle trees at the university campus (approx. $3 \mathrm{~m}$ high) were used. The life cycle experiments were carried out from mid-April to mid-May (fundatrix, fundatrigenia, winged females/alates) and in October (alate gynoparae, oviparae).

\section{Measuring the intensity of ant-attendance}

For these experiments 15 potted plants each of C. alba, C. arvense, and T. vulgare, and 7 pots (10 at the start of the experiment) with $V$. faba were used. Five plants of one species were placed in a planting pot containing an ant nest. Three $V$. faba plants were destroyed by phytophagous insects during the experiment. This trial was excluded from the evaluation of the relative ant-attendance but could be included into the data used for Table 1. Thus, we used in total 10 large sized planting pots with one ant colony in each pot. Workers of $L$. niger had access to each plant (and thus to the aphids) through an arrangement of wooden sticks. By this means, we could control for antattendance at each individual plant.

At the beginning of the experiment each aphid colony was standardized to 20 individuals. For each colony we counted the number of aphids as well as all ant workers which left the aphid colony (on the wooden sticks) during a 10-min interval every day (at the same daytime) over a period of three weeks. For evaluation, we separated this time interval: The first period (approx. one week) included the time before swarming of ant nests (i.e., ant nests contained sexuals and thus had a high demand for honeydew), the second period the time after swarming (i.e., with a reduced demand for honeydew). For comparison of host plants, we choose only the days $2-5$ before swarming and 6-9 after swarming of each colony to correct for a potential bias during pre-swarming, swarming and postswarming days.

Although we started with a standardized colony size, colonies grew differently during the nine days experimental period. To obtain a parameter for the intensity of ant-attendance that was independent of aphid colony size, we divided the number of ants by aphid colony sizes (ants per aphid = relative ant-attendance) as justified by the specific positive linear correlation of antattendance (Fischer et al., 2001) (see Results).

\section{Quantification of honeydew production}

We measured the honeydew collected by the ants by comparing the weight of ant workers with empty and filled gasters (Herzig, 1937). For experimental details see Fischer et al. (2001, 2002). Since all excreted honeydew droplets were collected by $L$. niger workers, we estimated the honeydew production of an individual aphid per hour using the following formula: [(average weight of ants with filled gasters leaving $A$. fabae - average weight of ants with empty gasters) $\times$ average number of ants leaving the colony of $A$. fabae]/number of aphids per $A$. fabae colony. Ants with empty gasters were collected when they approached the aphid colony via a stick. For each colony, we collected prior to the swarming period 20 ants with empty gaster and 20 ants with filled gaster. During this time period, the amount of honeydew collected in the gaster provides a good estimate of the maximum potential honeydew production (see Fischer et al., 2001).

\section{Honeydew collection}

Honeydew was collected twice a week directly from the anus using a microcapillary (volume 0.5 or $1 \mu \mathrm{l}$ ). After collection, samples were capped with Parafilm and stored at $-20^{\circ} \mathrm{C}$ until analysis. For a comparison between plants, 10-15 individual samples per plant species were analysed, collected from fourth instar larvae and adult aphids which provided the highest amount of honeydew. For a comparison between various morphs on E. europaeus, we obtained 5-12 samples per morph. Since the honeydew sugar composition does not differ significantly between aphid age classes (Fischer et al., 2001), a random selection of only two age classes should not bias the results.

\section{Analysis of honeydew sugar composition}

The honeydew was analyzed using high-pressure liquid chromatography (HPLC). A Carbo Pak ${ }^{\mathrm{TM}} \mathrm{PA} 100,4 \times 250 \mathrm{~mm}$ column (Dionex, Sunnyvale, CA) was used with a $0.5 \mathrm{M} \mathrm{NaOH}$ gradient of $3-70 \%$ in Milli-Q water for $30 \mathrm{~min}$ at a flow rate of 


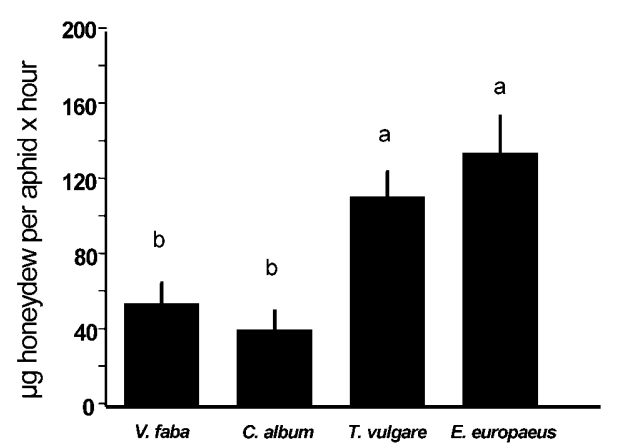

Fig. 1. Estimate of quantitative honeydew production of $A$. $f$. fabae (mean $\pm \mathrm{SE}$ ) feeding on various host plants. Means showing the same letter do not differ at $\mathrm{p}<0.05$ (MannWhitney-U test).

$1 \mathrm{ml} \times \mathrm{min}^{-1}$. For further details see Fischer \& Shingleton (2001) and Fischer et al. (2002). If relative sugar concentrations (\%) are presented in the result section, these calculations were based on the absolute concentrations in the respective sample.

\section{Statistical analysis}

For the statistical evaluation of the data we followed procedures outlined by Sokal \& Rohlf (1981) by using SPSS/PC 3.3 and WinSTAT 3.1. In Mann-Whitney-U tests, the Bonferroni correction was considered where necessary.

\section{RESULTS}

\section{Honeydew production of $A$. $f$. fabae on various host plants}

The honeydew production of $A$. $f$. fabae differed considerably between host plants (Fig. 1). Aphids feeding on the two annual plants $V$. faba and $C$. album produced less than half the amount of honeydew per aphid per hour than conspecifics on the perennial $T$. vulgare. Honeydew production of $A$. $f$. fabae virginoparae on the winter host $E$. europaeus was also high (135.5 $\mu \mathrm{g}$ per aphid per hour).

\section{Sugar concentration and sugar composition of the honeydew of $\boldsymbol{A}$. $\boldsymbol{f}$. fabae on various host plants}

Up to ten sugars could be identified in the honeydew of A. f. fabae on the various host plants. Honeydew was gen-

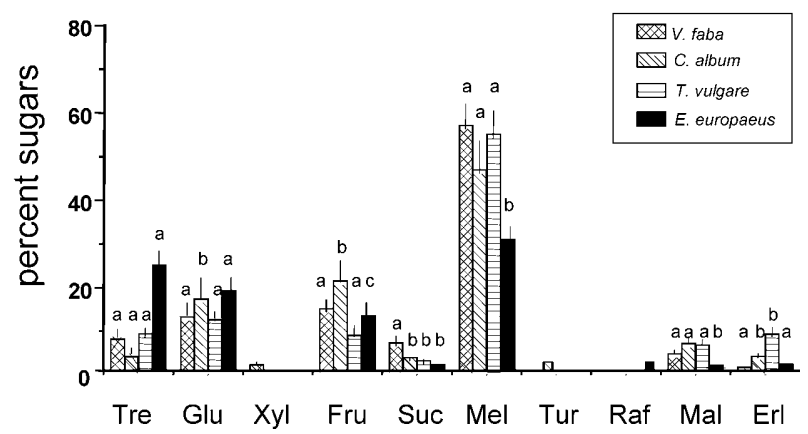

Fig. 2. Proportion (in $\%$ of total content) (mean \pm SE) of the identified sugars in the honeydew of $A$. $f$. fabae feeding on various host plants. Tre, trehalose; Glu, glucose; Xyl, xylose; Fru, fructose; Suc, sucrose; Mel, melezitose; Tur, turanose; Raf, raffinose; Mal, maltose; Erl, erlose. Means showing the same letter within a particular sugar do not differ significantly at $\mathrm{p}<$ 0.05 (Mann-Whitney-U test).

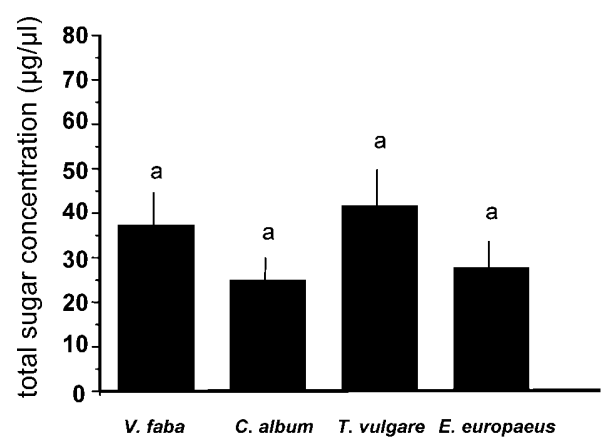

Fig. 3. Total sugar concentration (in $\mu$ g sugar per $\mu 1$ honeydew) (mean $\pm \mathrm{SE}$ ) in the honeydew of $A$. $f$. fabae feeding on various host plants. No means differ significantly at $\mathrm{p}<0.05$ (Mann-Whitney-U test).

erally dominated by the trisaccharide melezitose (Fig. 2), the disaccharide trehalose, and the monosaccharides glucose and fructose. Sucrose, maltose and erlose were present in low concentrations in all honeydew samples, whereas traces of xylose $(V . f a b a)$, turanose (C. album) and raffinose (E. europaeus) were detected only in single samples. The level of melezitose by far exceeded that of other sugars except for $A$. $f$. fabae on E. europaeus where the honeydew contained approximately equal amounts of melezitose, trehalose, glucose and fructose. The total sugar concentration of the honeydew (Fig. 3) did not differ significantly between various hosts (27 to $42 \mu \mathrm{g}$ sugar per $\mu$ l honeydew).

\section{Honeydew production and sugar composition of the honeydew for three subspecies of $\boldsymbol{A}$. fabae}

$A$. $f$. cirsiiacanthoides feeding on $C$. arvense produced an average of $151.5 \pm 35.5 \mu \mathrm{g}$ honeydew per aphid per hour (means $\pm \mathrm{SE}, \mathrm{n}=10$; not shown), whereas $A$. $f$. fabae feeding on $V$. faba produced ca. $55 \mu \mathrm{g}$ aphid ${ }^{-1} \cdot \mathrm{h}^{-1}$ only (see Fig. 1). The honeydew production of $A$. f. evonymi on E. europaeus was not measured. The honeydew of $A$. $f$. cirsiiacanthoides contained a significantly higher amount of total sugars (ca. $70 \mu \mathrm{g} \cdot \mathrm{ll}^{-1}$ ) than the honeydew of $A$. $f$. fabae on its summer host (Fig. 4; see also Fig. 3). A similar concentration of total sugars as for $A$. $f$. fabae on its summer host was present in the honeydew of

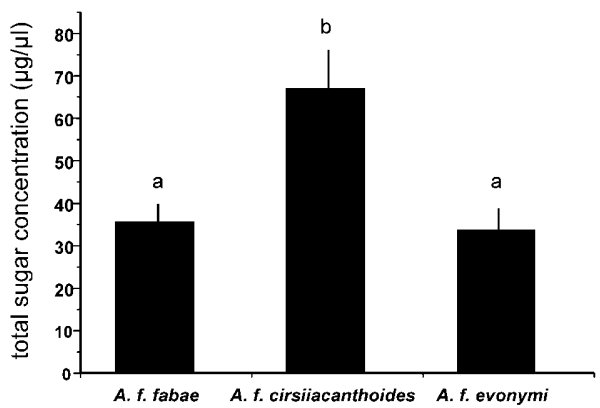

Fig. 4. Total sugar concentration (in $\mu$ g sugar per $\mu 1$ honeydew) (mean $\pm \mathrm{SE}$ ) in the honeydew of three subspecies of $A$. fabae feeding on their respective summer hosts. Means sharing the same letter do not differ significantly at $\mathrm{p}<0.05$ (MannWhitney-U test). 


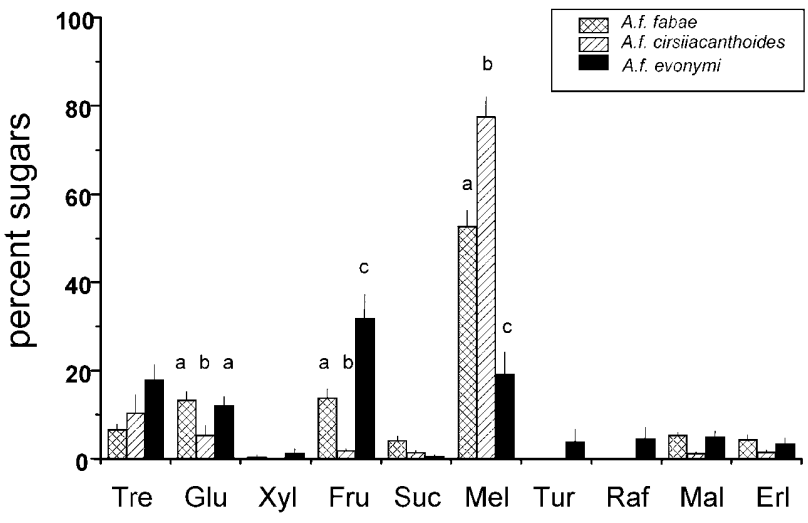

Fig. 5. Proportion (in $\%$ of total content) (mean $\pm \mathrm{SE}$ ) of the identified sugars in the honeydew of three subspecies of $A$. fabae feeding on their respective summer hosts. For details see Fig. 2. Means sharing the same letter do not differ significantly at $\mathrm{p}<0.05$ (Mann-Whitney-U test).

A. f. evonymi on spindle trees. The honeydew of $A$. f. cirsiiacanthoides on the creeping thistle contained the highest proportion of melezitose ( $80 \%$ of total sugars) (Fig. 5), whereas in the honeydew of $A$. f. evonymi fructose was dominant (34\%). Moreover, this honeydew contained considerable amounts of turanose and raffinose, which were not detected in either of the other subspecies feeding on herbaceous plants (but found in a sample of $A$. $f$. fabae on E. europaeus, see above).

\section{Ant-attendance of $\boldsymbol{A}$. fabae ssp. on herbaceous summer hosts by $L$. niger}

In a first set of experiments we showed that in three of the four host plants a positive correlation existed between aphid colony size and the number of attending ants (Table 1). Within our range of colony sizes the relationships were linear. Since ants began to swarm during the observation period (end of July), the observation period had to be divided into two parts: Pre-swarming at day 2-5 and swarming at days 6-9 (Table 2). Before swarming, significant differences in ant-attendance were observed between aphids on the three host plants with highest intensity of visiting ants for the $A$. $f$. cirsiiacanthoides colonies on $C$. arvense and least intensity of antattendance for $A$. $f$. fabae on $T$. vulgare. During swarming aphids on $C$. arvense were still more attractive for ants than on the other two host plants.
TABLE 1. Correlation of ant-attendance (L. niger) with the number of aphids in $A$. fabae ssp. colonies on four herbaceous summer host plants; $n$, number of observations.

\begin{tabular}{lccc}
\hline Plant species & $\mathrm{r}_{\mathrm{s}}$ & $\mathrm{n}$ & $\mathrm{p}$ \\
\hline C. album & 0.511 & 90 & $<0.001$ \\
T. vulgare & 0.638 & 87 & $<0.001$ \\
C. arvense & 0.636 & 90 & $<0.001$ \\
V. faba & 0.339 & 21 & 0.132 \\
\hline
\end{tabular}

\section{Sugar composition of the honeydew from various generations of $A$. $f$. fabae}

Total sugar concentration in the honeydew of $A$. $f$. fabae on E. europaeus changed significantly during the experimental period (Fig. 6). Sugar concentration was very low $\left(<10 \mu \mathrm{g} \cdot \mu \mathrm{l}^{-1}\right)$ in the fundatrix generation which had hatched from overwintering eggs in April, but increased to $25-35 \mu \mathrm{g} \cdot \mathrm{l}^{-1}$ in the following two generations (fundatrigenia, alates; April to mid-May). Individuals of the third winged generation usually migrate to the summer host. Alate gynoparae that had returned from the summer host at the end of the vegetation period (October) again showed a low amount of sugars in the honeydew (ca. $10 \mu \mathrm{g} \cdot \mu \mathrm{l}^{-1}$ ), but another increase could be observed in the oviparae by the end of October. The percent distribution of the sugars in the honeydew did not significantly change over the generations (Table 3 ) except that the honeydew of the fundatrigenia contained about twice the amount of melezitose as in the other generations (Fig. 7).

\section{DISCUSSION}

The mutualism between aphids and ants is influenced by a number of biotic factors. For the ant, the quantity and the quality of the supplied honeydew are important (Bristow, 1984), but also the predictability of the honeydew source (Noe \& Hammerstein, 1994). The quantity of the honeydew produced by aphids as well as the honeydew composition varies among species. Within given species, the rate of honeydew production and the sugar composition of the honeydew may vary along their developmental (seasonal) cycle and between age classes (Hertel \& Kunkel, 1977; Fischer et al., 2002), but also with variation in the host plant (Hendrix et al., 1992; Fischer \& Shingleton, 2001). Furthermore, honeydew production and honeydew composition change in response to interactions with ants (Del-Claro \& Oliveira, 1993; Fischer et al., 2001).

TABLE 2. Relative ant-attendance (ants per aphid) of $A$. fabae ssp. colonies on four herbaceous host plants before and during the swarming period of $L$. niger (mean $\pm \mathrm{SE}$ ). Means within each column that share the same letter do not differ significantly at $\mathrm{p}<0.05$ (Mann-Whitney-U test). There were no data for $V$. faba for the second period (see Methods).

\begin{tabular}{lcccc}
\hline Plant species & $\mathrm{n}$ & $\begin{array}{c}\text { Relative ant-attendance } \\
\text { (pre-swarming days 2-5) }\end{array}$ & $\mathrm{n}$ & $\begin{array}{c}\text { Relative ant-attendance } \\
\text { (swarming days 6-9) }\end{array}$ \\
\hline C. album & 60 & $0.144 \pm 0.110^{\mathrm{b}}$ & 45 & $0.052 \pm 0.050^{\mathrm{a}}$ \\
T. vulgare & 57 & $0.094 \pm 0.008^{\mathrm{a}}$ & 42 & $0.072 \pm 0.081^{\mathrm{a}}$ \\
C. arvense & 60 & $0.187 \pm 0.120^{\mathrm{c}}$ & 45 & $0.103 \pm 0.107^{\mathrm{b}}$ \\
V. faba & 45 & $0.115 \pm 0.044^{\mathrm{b}}$ & - & - \\
\hline
\end{tabular}




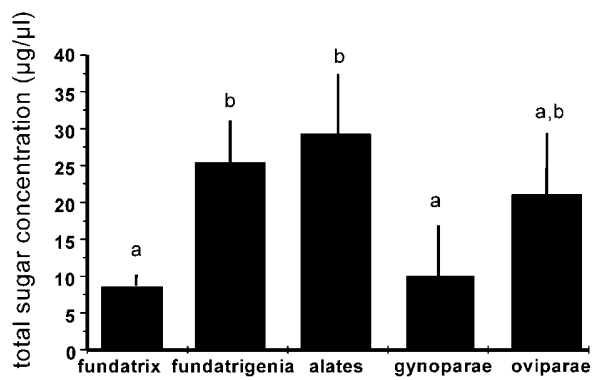

Fig. 6. Total sugar concentration (in $\mu$ g sugar per $\mu 1$ honeydew) (mean $\pm \mathrm{SE}$ ) in the honeydew of various generations of $A$. $f$. fabae on their winter host, E. europaeus. Means sharing the same letter do not differ significantly at $\mathrm{p}<0.05$ (MannWhitney-U test).

Ants respond most intensively to honeydew containing high amounts of the trisaccharide melezitose (Kiss, 1981; Völkl et al., 1999). Some aphids, such as Metopeurum fuscoviride on tansy, excrete honeydew that contains up to $70 \%$ melezitose, and such species are strongly attended by ants (Fischer et al., 2001, 2002). Other species, for example Macrosiphoniella tanacetaria on tansy, contain virtually no melezitose in their honeydew, and are not usually tended by ants (Hendrix et al., 1992; Völkl et al., 1999). In a recent study on the hierarchy of antattendance in eight species of aphids feeding on tansy (Woodring et al., 2004) it was demonstrated that a combination of the sugar richness of the honeydew excreted by the aphid (rate of honeydew production $\times$ total sugar concentration in the honeydew) together with a high content of the attractant sugar melezitose determines the extent of ant-attendance. There was no evidence that any single amino acid or group of amino acids in the honeydew act as an attractant for ant-attendance in these aphids.

In $A$. $f$. fabae feeding on four different herbaceous host plants, honeydew production differed significantly. For example, the amount of honeydew produced by $A$. $f$. fabae feeding on tansy was more than twice (ca. $110 \mu \mathrm{g}$ per aphid $\mathrm{h}^{-1}$ ) as high as when feeding on goosefoot, $C$. album (ca. $40 \mu \mathrm{g}$ per aphid $\cdot \mathrm{h}^{-1}$ ). The honeydew of $A$. $f$. fabae on tansy also contained a higher amount of total

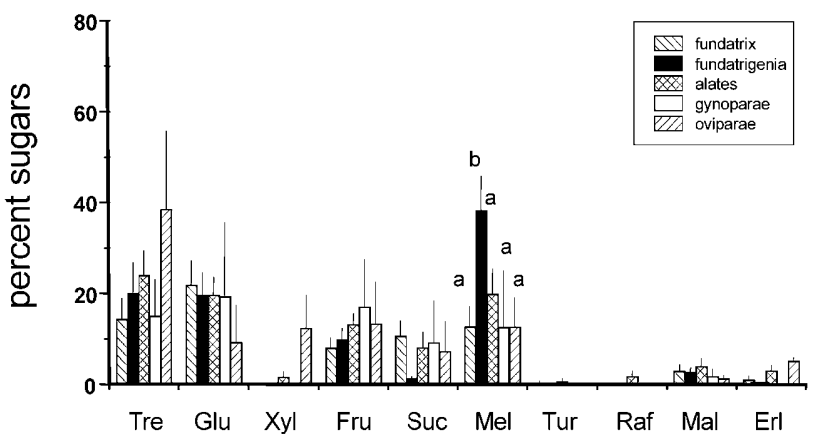

Fig. 7. Proportion (in $\%$ of total content) (mean \pm SE) of the identified sugars in the honeydew of various generations of $A$. $f$. fabae on E. europaeus. Means sharing the same letter within the trisaccharide melezitose do not differ significantly at $\mathrm{p}<0.05$ (Mann-Whitney-U test).
TABLE 3. Kruskal-Wallis-ANOVA $\left(\mathrm{K}-\mathrm{W} \chi^{2}\right)$ for the proportion of sugars in the honeydew from various generations of $A$. $f$. fabae on the spindle, E. europaeus. Tre, trehalose; Glu, glucose; Fru, fructose; Suc, sucrose; Mel, melezitose; Mal, maltose; Erl, erlose.

\begin{tabular}{cccc}
\hline Sugars & $\chi^{2}$ & $\mathrm{df}$ & $\mathrm{p}$ \\
\hline$\%$ Tre & 5.21 & 4 & 0.266 \\
$\%$ Glu & 1.51 & 4 & 0.825 \\
\% Fru & 3.05 & 4 & 0.550 \\
\% Suc & 1.22 & 4 & 0.875 \\
\% Mel & 9.09 & 4 & 0.050 \\
$\%$ Mal & 2.05 & 4 & 0.727 \\
$\%$ Erl & 8.40 & 4 & 0.078 \\
\hline
\end{tabular}

sugars, and a slightly higher portion of melezitose, than when feeding on $C$. album. Another subspecies of $A$. fabae, A. $f$. cirsiiacanthoides, which occurs on the creeping thistle, $C$. arvense, during the summer, produced as much as $150 \mu \mathrm{g}$ honeydew per aphid per hour, and this honeydew contained by far the highest amount of total sugars (ca. $67 \mu \mathrm{g} / \mu \mathrm{l}$ ) as well as the higest portion of melezitose $(80 \%)$. The calculated value for richness of honeydew was 8.7 , compared to 3.9 for $A$. f. fabae on tansy, and only 1.0 for $A$. fabae on goosefoot. The results confirm our earlier hypothesis that the sugar richness of the honeydew along with the presence of melezitose are the critical factors in determining the extent of antattendance. Indeed, in the present study the highest intensity of visiting ants was observed for $A$. $f$. cirsiiacanthoides colonies on $C$. arvense. However, richness of honeydew does not explain the differences between goosefoot and tansy. Although having a lower richness of honeydew, aphids on goosefoot were less attended than aphids on tansy. We hypothesize that differences in plant structure might contribute to this finding. Ants have much better access to the aphid colonies feeding on goosefoot leaves and inflorescences than on the stem of tansy. A. f. evonymi, which is found on the woody spindle tree all year round, produced a honeydew which was low in total sugars and contained only low amount of melezitose with fructose being the dominant sugar. The sugar quality did not change during the season (Fischer, 2001). Ants were seldom observed visiting $A . f$. evonymi (Börner, 1952, Völkl \& Fischer, unpubl.).

There are also important ecological implications. First, a higher ant-attendance should provide a better protection against natural enemies such as predators and parasitoids (Fischer et al., 2001). Second, there might exist indirect effects between colonies of the same species on different host plant species. Considering that ants compete for mutualists (e.g., Del-Claro \& Oliveira, 1993; Fischer et al., 2001) we may hypothesize that aphid colonies on creeping thistle might distract ants from neighbouring aphid colonies on tansy or goosefoot which often grow in the same habitat. Again, these colonies may suffer from increased predation and parasitism (Fischer et al., 2001) due to reduced ant guarding. Thus, they may have lower 
overall fitness since they will be expected to produce fewer sexuals in autumn.

In another experiment, we studied the honeydew quality in various generations of $A$. $f$. fabae on their winter host, E. europaeus. In contrast to $A$. $f$. evonymi feeding on the spindle tree, honeydew of $A$. $f$. fabae showed drastic changes in sugar content as well as in sugar composition during the season. The honeydew of the fundatrigenia and alates in late spring contained significantly higher total sugar concentrations than of the other generations and the honeydew of the fundatrigenia also was the richest in melezitose. These two generations fed on the developing leaves, and thus we might expect that plant metabolism affects even honeydew concentration. This assumption is supported by the differences between gynoparae and oviparae; the latter fed on senescent leaves from which nutrients were redirected to woody plant parts. Besides the common mono-, di-, and trisaccharides, significant amounts of sugar alcohols were detected in the honeydew samples of all generations (Fischer, 2001), as well as an unknown sugar conjugate which is currently under structure elucidation.

ACKNOWLEDGEMENTS. We thank to J. Woodring (Baton Rouge, USA and Bayreuth, Germany) for critical comments on the manuscript. Financial support was provided by the German Research Councel (DFG, Ho 631/18-1,2 and GK 678/1).

\section{REFERENCES}

Auclair J.L. 1963: Aphid feeding and nutrition. Annu. Rev. Entomol. 8: 439-490.

Bonser R., Wright P.J., Bament S. \& Chukwu U.O. 1998: Optimal patch use by foraging workers of Lasius fuliginosus, L. niger and Myrmica ruginodis. Ecol. Entomol. 23: 15-21.

Börner C. 1952: Aphidae Europae Centralis. Mitt. Thüring. Bot. Ges. 4: 1-184.

BRISTOw C. 1984: Differential benefits from ant-attendance to two species of Homoptera on New York ironweed. J. Anim. Ecol. 53: 715-726.

Del-Claro K. \& Oliveira P.S. 1993: Ant-Homoptera interactions: do alternative sugar sources distract tending ants? Oikos 68: $202-206$.

Douglas A.E. 1993: The nutritional quality of phloem sap utilized by natural aphid populations. Ecol. Entomol. 18: 31-38.

Engel V., Fischer M.K., WÄCKers F.L. \& VÖLKL W. 2001: Interactions between extrafloral nectaries, aphids and ants: are there competition between plant and homopteran sugar sources? Oecologia 129: 577-584.
FISCHER M.K. 2001: Die Zuckerzusammensetzung des Honigtaus bei verschiedenen Blattlausarten und die Konsequenzen für den Mutualismus Blattlaus-Ameise. PhD Thesis, University of Bayreuth, Germany.

Fischer M.K. \& Shingleton A.W. 2001: Host plant and ants influence the honeydew sugar composition of aphids. Funct. Ecol. 15: 544-550.

Fischer M.K., Hoffmann K.H. \& VöLKL W. 2001: Competition for mutualists in an ant-homopteran interaction mediated by hierarchies of ant attendance. Oikos 92: 531-541.

Fischer M.K., VölkL W., Schopf R. \& Hoffmann K.H. 2002: Age-specific patterns in honeydew composition in the aphid Metopeurum fuscoviride: implications for ant-attendance. $J$. Insect Physiol. 48: 319-326.

HendRix D.L., Wei Y. \& Legget J.E. 1992: Homopteran honeydew is determined by both the insect and the plant species. Comp. Biochem. Physiol. (B) 101: 23-27.

Hertel R. \& Kunkel H. 1977: Einige Faktoren, welche die Honigtauzusammensetzung natürlich wie auch holidisch ernährter Aphidenlarven beeinflussen. Apidologie 8: 427-436.

Herzig J. 1937: Ameisen und Blattläuse. Z. Angew. Entomol. 24: $367-435$.

KIss A. 1981: Melezitose, aphids and ants. Oikos 37: 382

Maurizio A. 1985: Honigtau-Honigtauhonig. In Kloft W.J., Maurizio A. \& Kaeser W. (eds): Waldtracht und Waldhonig in der Imkerei. Ehrenwirth, München, pp. 268-295.

Noe R. \& Hammerstein P. 1994: Biological markets: supply and demand determine the effect of partner choice in cooperation, mutualism and mating. Behav. Ecol. Sociobiol. 35: 1-11.

Powell G. \& Hardie J. 2000: Host-selection behaviour by genetically identical aphids with different plant preferences. Physiol. Entomol. 25: 54-62.

Powell G. \& Hardie J. 2001: A potent, morph-specific parturition stimulant in the overwintering host plant of the black bean aphid, Aphis fabae. Physiol. Entomol. 26: 194-201.

Sokal R.R. \& Rohlf 1995: Biometry. Freeman, New York, 887 pp.

VölkL W., Woodring J., Fischer M., Lorenz M.W. \& HofFMANN K.H. 1999: Ant-aphid mutualisms: the impact of honeydew production and honeydew sugar composition on ant preferences. Oecologia 118: 483-491.

WAY M.J. 1963: Mutualism between ants and honeydewproducing Homoptera. Annu. Rev. Entomol. 8: 307-344.

Woodring J., Wiedemann R., Fischer M.K., Hoffmann K.H. \& VöLKL W. 2004: Honeydew amino acids in relation to sugars and their role in the establishment of ant-attendance in eight species of aphids feeding on tansy (Tanacetum vulgare). Physiol. Entomol. 29: 311-319.

Received July 26, 2004; revised and accepted November 15, 2004 